\title{
Internet Banking Need of Current Scenario
}

\author{
Neena Brar ${ }^{1}$, Jaspreet Singh ${ }^{1}$ \\ ${ }^{1}$ Lecturers, Khalsa College, Patiala (PB) India
}

\begin{abstract}
Banking in India originated in the last decades of the 18th century. The IT revolution influenced the Indian banking system a lot. The use of computers had led to existence of online banking in India. The use of modern innovation and computerization of the banking sector of India has increased many folds after the economic liberalisation of 1991 as the country's banking sector has been exposed to the world's market. The Indian banks were finding it hard to compete with the international banks in terms of the customer service without the use of the information technology and computers. Internet banking as a medium of delivery of banking services and as a strategic tool for business development, has gained wide acceptance internationally and is fast catching up in India with more and more banks entering the fray. In the light of this background, the objective of this paper is to study the perceived usefulness of Internet Banking. This paper tries to know the level of awareness among customers. This paper also tries to check the perception of risks closely connected with Internet Banking and study the scope of Internet Banking, so that companies can fulfill their duty in an appropriate and suitable manner.
\end{abstract}

Keywords revolution, online banking, innovation, liberalization

\section{INTRODUCTION}

The twenty-first century is characterised by the use of information technology which has revolutionized not only our working patterns but our style of living also. A new era of banking, coined "Internet banking" has come into existence, where customers can perform their financial transactions electronically over the internet through their personal computer or laptop at a time convenient and suitable to them, without visiting concerned bank and thus, in this manner they can save their precious time and utilize in other crucial tasks. Furthermore, customer is expected to perform at least one of the following transactions online, namely viewing account balance and transaction histories, paying bills, transferring funds between accounts, ordering cheques, managing investments and stock trading.

Internet banking as a medium of delivery of banking services and as a strategic tool for business development, has gained wide acceptance internationally and is progressing in India as more and more banks entering the fray. India can be said to be on the threshold of a major banking revolution with net banking having already been unveiled.

Internet banking is defined as "the provision of retail and small value banking products and services through electronic channels. Such products and services can include deposit-taking, lending, account management, the provision of financial advice, electronic bill payment, and the provision of other electronic payment products and services such as electronic money."

Online banking or Internet banking allows customers of a financial institution to conduct financial transactions on a secure website operated by the institution, which can be a retail or virtual bank, credit union or building society. 


\section{MAIN OBJECTIVES OF THE STUDY}

To analyze the perceive usefulness of Internet Banking.

1. To know the level of awareness among customers.

2. To check the perception of risks associated with Internet Banking.

3. To examine the reach of Internet Banking.

\section{REVIEW OF LITERATURE}

Divya Singhal \& V.Padhmanabhan (2008) this study has successfully examined the major factors responsible for IB based on respondent's perception on various internet applications. This study also examined whether there is any relation with the demographic variable (gender) \& respondent's perception about IB; whether the users \& non-users perceptions are different.

David D. VanHoose (2009) this paper reviews what economists have learned about internet banking. The paper begins by surveying evidence regarding the fundamental motivations for banks to offer services via the internet and for their customers to utilize the services. The paper next evaluates the current evidence on how internet banking has affected the performances of traditional banking institutions. Furthermore, it examines recent concerns about the possibility that deposits raised through internet channels are potentially more susceptible to sudden withdrawals that could result in runs on banks. The paper concludes by summarizing the main points and considering future directions for research on this topic.

Neha Dixit \& Dr. Saroj K.Datta (2010) investigated the factors which are affecting the acceptance of i-banking services among adult customers and also indicate level of concern regarding security and privacy issues in Indian context. The finding depicts many factors like security \&privacy, trust, innovativeness, familiarity, awareness level increase the acceptance of i-banking services among Indian customers. The finding shows that in spite of their security and privacy concern, adult customers are willing to adopt online banking if banks provide him necessary guidance.

Rahmath Safeena, Abdulla \& Hema Date (2010) concluded that perceived usefulness, perceived ease of use, consumer awareness and perceived risk are the important determinants of online banking adoption. They concludes that majority of customers are accepting online banking because of many favorable factors. Analysis concluded that usefulness, ease of use of the system awareness about online banking and risks related to it are the main perusing factors to accept online banking system. These factors have a strong and positive effect on customers to accept online banking system

\section{RESEARCH METHODOLOGY}

Scope of the study The scope of the study is restricted to the various districts of Punjab. For the collection of the primary data the study will be confined to Malwa region of Punjab state only.

Research Design The study being undertaken is Descriptive in nature. The major purpose of descriptive research is description of the state of affairs as it exists at present, while studying the research problem, scientific method is followed.

Sampling Unit In this study, the sampling unit was the people of Punjab.

Sample Size The sample size was so selected that it could be adequate enough to represent the whole population, and also give the true picture. The total sample size was restricted to 225 .

Sampling Design Keeping in Mind the nature of data required for the study, random sampling technique has been used. The respondent for the survey has been selected from the selected districts of Malwa Region 
of Punjab; like Patiala, Sangrur, Mansa and Fatehgarh Sahib.

Data Collection In the present study I have made use of primary data collected through questionnaire. I also used information available on web-portals.

Questionnaire Method The primary data was collected by administering structured questionnaire to the people who have a bank account.

Nature of the Study The "Descriptive Research Study" has been used. The basic aim is to gain familiarity and to achieve new insights along with describing the existing facts.

Statistical Tools and Techniques Statistical tool of percentage analysis has been used for the analysis of the data and to draw a meaningful conclusion there from.

\section{Limitations of the study}

1. The present study is based on the data collected from sample districts of Punjab state only and the result may vary from other states or the national average.

2. The result of this study shows that Perceived ease of usefulness, reach of Internet Banking, risks associated with this and customers attitude are the important determinants of online banking adoption.

3. The replication of this study on a wider scale with more IB customers and with different national cultures is essential for the further generalization of the findings.

4. The time limit is also an important factor which acts as a barrier in the whole research process. The shortage of time period forces to do research on small size of sample.

5. Most of the respondents due to lack of awareness and security factor fear to use Internet Banking, so fair conclusion is not done as per the responses of few ones only. So there is scope for further investigation at larger scale \& by taking more respondents who use Internet Banking.

\section{DATA ANALYSIS \& INTERPRETATION}

\section{Profile of the Respondents}

Table 5.1 shows the classification of respondents in sample by age group. $20 \%$ respondents were in the age group of 18-35 years, $33.33 \%$ respondents were in the age group of 36-45 years and $22.67 \%$ respondents were in the age group of $46-55$ years. In the senior category $17.78 \%$ respondents were in the age group of 56-65 years and $6.22 \%$ respondents were above 65 years.

\section{Table 5.1 Demographic Profile}

\begin{tabular}{|c|c|c|c|}
\hline & Category & Nos. & \%age \\
\hline Age & 18 to 35 years & 45 & $20 \%$ \\
& 36 to 45 years & 75 & $33.33 \%$ \\
& 46 to 55 years & 51 & $22.67 \%$ \\
& 56 to 65 years & 40 & $17.78 \%$ \\
& Above 65 years & 14 & $6.22 \%$ \\
& Total & $\mathbf{2 2 5}$ & $\mathbf{1 0 0} \%$ \\
\hline Educational & Under Matric & 67 & $29.77 \%$ \\
Qualification & Matric & 99 & $44 \%$ \\
& Graduate & 45 & $20 \%$ \\
& Post Graduate/professional & 14 & $6.22 \%$ \\
& Total & $\mathbf{2 2 5}$ & $\mathbf{1 0 0} \%$ \\
\hline Income & Below Rs. 50,000 & 14 & $6.62 \%$ \\
& Rs.50,000-1,000,00 & 50 & $22.22 \%$ \\
\hline
\end{tabular}




\begin{tabular}{|c|c|c|c|}
\hline & Rs. $1,00,000-2,00,000$ & 112 & $49.78 \%$ \\
& Rs.2,00,000-5,00,000 & 44 & $19.56 \%$ \\
& Above Rs. 5,00,000 & 5 & $2.22 \%$ \\
& Total & $\mathbf{2 2 5}$ & $\mathbf{1 0 0} \%$ \\
\hline
\end{tabular}

Under the education level classification, out of these $29.77 \%$ respondents were Under Matric, $44 \%$ respondents were Matric, $20 \%$ respondents were Graduate and $6.22 \%$ respondents were from Post Graduate.

Out of these 225 respondents in the sample $6.62 \%$ respondents were from below Rs. 50,000 per annum income category, $49.78 \%$ respondents were from Rs. 1,00,00-Rs. $2,00,000$ per annum income category, 19.56 $\%$ respondents were from Rs. 2,00,000-Rs. $5,00,000$ per annum income category and few $2.22 \%$ respondents were from above Rs. $5,00,000$ per annum income category.

\section{FINDINGS}

1. $30 \%$ of the respondents say yes they do use internet banking and $70 \%$ of the respondents say they don't use internet banking.

2. $40 \%$ of the respondents say that they have never heard about internet banking, $33.33 \%$ of the respondents say that they don't have time to open an account and $26.67 \%$ of the respondents say that they don't see any real value of having such account.

3. $66.67 \%$ of the respondent's replies that very likely they would like to open an account within next 12 months, $33.33 \%$ of the respondent's replies that somewhat likely they would like to open an account within next 12 months.

4. $70 \%$ of the respondents reply that they used I-Banking from last one year , 20\% of the respondents reply that they used I-Banking from last 6 to 12 months and only $10 \%$ says that they were using it from the last 0-3 months.

5. Respondents used IB for different purposes like $23.54 \%$ of the respondents reply that they use IB for tax filing, 70\% of the respondents reply that they use IB for on-line bill payments, $65 \%$ of the respondents reply that they use IB for the purchasing of financial products, $24.36 \%$ of the respondents reply that they use IB for checking their balances, $63.25 \%$ of the respondents reply that they use IB for inter-account transfers.

6. $40 \%$ of the respondents say that they use telephone banking only once a month, $45 \%$ of the respondents reply that they use telephone banking for 1 to 3 times in a month, $10 \%$ of the respondents say that they use telephone banking for 3 to 8 times in a month, $5 \%$ of the respondents reply that they use telephone banking for 8 to 12 times in a month.

7. $80 \%$ respondents consider internet banking is safe \& secure for their financial transactions, $20 \%$ respondents consider risk factor always exists while using internet banking and they don't find it secure.

8. $15 \%$ of the respondents agreed that they face few problems while using IB, $75 \%$ of the respondents agreed that it is simple \& easy to operate \& they don't face any problems while using IB.

9. $45 \%$ of the respondents say that there is need to give information about IB services in their area, $55 \%$ of the respondents refuse to give any kind of information in their area.

10. $100 \%$ of the respondents agree with this that IB make their life more easy \& comfortable.

11. $40 \%$ of the respondents agree to provide credit card \& purchase information over the internet when this information is encrypted, $60 \%$ of the respondents refuse to give credit card \& purchase information over the internet when this information is encrypted.

12. $67.45 \%$ respondents agreed to provide credit card information and personal 
information over the Internet to a Web vendor who is well known and reliable, $32.55 \%$ of refuses to provide credit card information and personal information over the Internet to a Web vendor who is well known and reliable.

13. $50 \%$ of respondents have an Internet Bank account in State Bank of Patiala, $20 \%$ of respondents have an IB account in State Bank of India, $20 \%$ of respondents have account in HDFC bank \& $10 \%$ of respondents have an internet bank account in Axis Bank.

14. $52.67 \%$ of respondents replied that they opened \& used IB Account for their convenience, $23.22 \%$ of respondents replied that they use it for easiness of their transactions \& time saving, $20 \%$ of respondents answered that they use it for safety purposes, $4.11 \%$ of respondents replied that they use IB for the Interest.

15. $65 \%$ of the respondents don't feel any kind of risk by using IB services as compared to traditional banking, $35 \%$ of respondents feel that various risks are associated like fraud in their transactions, manipulation of their account, etc.

\section{CONCLUSION}

While investigating all the variables and the responses by consumers, this study reveals that the perception of the consumers can be changed and can be made positive by awareness program, friendly usage, fewer charges, proper security, and the best response to the services offered.

In case of the consumers who don't use Internet banking services, having all facilities at their disposal, technology was not the biggest issue. The first thing that all bankers should concern about is the requirement of awareness. Even though these people are inclined towards the manual banking, these can be turned to potential customers, it is well proven thing, which says the surrounding influences the individual's behaviour or in our region only environment that surrounds the public determines the behaviour and decisions of the individuals. So if a consumer sees most of his colleagues or friends who surround him/her using Internet banking then it may influence his/her decision to follow Internet banking option.

\section{SUGGESTIONS}

This study confirmed that one way to shift people from non users segment to users segment can be educating them and making them aware about the services provided \& benefits of using these services.

If banks arrange workshops in Financial Institutions \& other places, where knowledge about the benefits of Internet Banking \& training is imparted to use Internet Banking \& also open Internet Bank Accounts simultaneously then this will act as boon for Banks..

By making Internet Banking operations more easy, the Banks can enhance the level of users \& can also give more satisfaction to existing ones as they face numerous problems while using Internet Banking.

The security for their funds is the main factor due to which people fear to open an Internet Bank Account. Thus, by giving them assurance that their funds are secured even if they resort to Internet Banking could assist Banks to increase their customer's percentage.

The Government can also play a vital role in the promotion of Internet Banking by making strict rules \& regulations in case any fraud arises. No doubt IT Act plays an important role but there is need of more Government enrolment because it is good for Indian economy to accelerate their growth rate.

If people associate themselves with technology \& its upcoming features ,they can avail lots of benefits from new technology and it can play significant role in the promotion of Internet Banking. It is well proved that activities in which people show keen interest, they use those activities at their 
best as compared to those where pumping is done to do so.

The instructions to use Internet Banking services should be made available in different languages so that it will be more convenient for the customers to use Internet Banking services.

\section{REFERENCES}

1. Agarwal, R, Rastogi, S \& Mehrotra, A.,"Customers 'perspectives regarding e-banking in an emerging economy," Journal of Retailing and Consumer Services, vol. 16, pp. 340-351, 2009.

2. Aladwani, A., "Online Banking: A Field Study of Drivers, Development Challenges and Expectations," International Journal of Information Management, vol. 21, pp. 213-225, 2001.

3. Aldas-Manzano, J, LassalaNavarre, C, Ruiz-Mafe, C \& SanzBlas, S., "The role of consumer innovativeness and perceived risk in online banking usage," International Journal of Bank Marketing, vol. 27, no. 1, pp. 5375, 2009.

4. Al-Hajri, $\mathrm{S} \&$ Tatnall, A., "Technological Innovation and the Adoption of Internet Banking in Oman," The Electronic Journal for Virtual Organizations and Networks, vol. 10, pp. 59-83, 2008.

5. Alsajjan, B \& Dennis, C., "Internet Banking Acceptance Model: CrossMarket Examination,"Journal of Business Research. 2009.

6. Al-Somali, S, Gholami, R \& Clegg, B., "An Investigation into the Acceptance of Online Banking in Saudi Arabia," Technovation, vol. 29, pp. 130-141, 2009.

7. Amin, H., "Internet Banking Adoption among Young
Intellectuals," Journal of Internet Banking and Commerce, vol. 12, no. 3.2007

8. Chau, P \& Lai, V., “An Empirical Investigation of the Determinants of User Acceptance of Internet Banking," Journal of Organizational Computing and Electronic Commerce, vol. 13, no. 2, pp. 123-145, 2003.

9. Rahmath Safeena; Hema Date \& Abdullah Kammani; "Internet Banking adoption in an Emerging Economy," International Arab Journal of E-Technology, volume2; no.1, jan. 2011.

10. Rajesh Kumar Srivastava; "Customer's Perception on Usage of Internet Banking" Innovative Marketing, volume3; issue4, 2007.

11. Dr.A Vinaya Gamoorthy \& K.Senthilumar;"Role of reach of Internet Banking in India”Journal of Business Research.2008.

12. https://www.Indianbanks.net.in/jsp/ startib.jsp

13. http://www.encrypt.standardbank.c o.za/

14. https://www.banknetindia.com/ban king/bkngintro.htm

15. https//www.hsbc.co.in/ 